\title{
GESSO AGRÍCOLA E RENDIMENTO DE GRÃOS DE SOJA NA REGIÃO DO SUDOESTE DE GOIÁS ${ }^{(1)}$
}

\author{
Lucimeire Neis $^{(2)}$, Helder Barbosa Paulino ${ }^{(3)}$, Edicarlos Damacena de \\ Souza $^{(3)}$, Edésio Fialho dos Reis ${ }^{(3)}$ \& Flávio Araújo Pinto ${ }^{(4)}$
}

\begin{abstract}
RESUMO
O revolvimento de áreas em plantio direto (PD) há vários anos e o uso de gesso agrícola são práticas observadas entre os produtores na região do sudoeste de Goiás. Este trabalho foi realizado com o objetivo de avaliar o efeito da aplicação de doses de gesso agrícola $\left(0,1,2,4\right.$ e $\left.6 \mathrm{Mg} \mathrm{ha}^{-1}\right)$ em alguns atributos químicos em profundidade no solo e no rendimento de grãos de soja em plantio direto com revolvimento (PDR) e sem revolvimento (PDS). O delineamento foi em blocos completos ao acaso, em esquema de parcelas subsubdivididas, com quatro repetições. A área vinha sendo conduzida há vários anos em $\mathrm{PD}$, em um Latossolo Vermelho-Amarelo distrófico textura argilosa, no sudoeste goiano, com os teores de $\mathrm{Ca}^{2+}, \mathrm{Mg}^{2+}, \mathrm{K}^{+}$, sulfato e CTC efetiva sendo determinados nas camadas de $0-5,5-$ 10, 10-20 e 20-40 cm. Observou-se que no PDS a maior concentração dos cátions e do sulfato ocorreu na camada de 0-5 cm, enquanto no PDR o sulfato se concentrou na de 20-40 cm. O maior rendimento de grãos de soja ocorreu no PDS, porém não houve influência das doses de gesso.
\end{abstract}

Termos de indexação: cátions, cerrado, sulfato.

\footnotetext{
(1) Parte da Tese de Mestrado da primeira autora apresentada à Universidade Federal de Goiás - UFG. Recebido para publicação em março de 2009 e aprovado em novembro de 2009.

(2) Mestranda no Programa de Pós-Graduação em Agronomia, Universidade Federal de Goiás - UFG. Rua Riachuelo, Caixa Postal 03, CEP 75804-020 Jataí (GO). E-mail: nina.neis@hotmail.com

(3) Professor do Programa de Pós-Graduação em Agronomia, UFG. E-mails: helderlino51@yahoo.com.br; edicarlos@pq.cnpq.br; edesio7@brturbo.com.br

(4) Discente do Curso de Agronomia, UFG/Jataí. E-mail: flavioaraujo10@gmail.com
} 


\title{
SUMMARY: GYPSUM IN MANAGEMENT SYSTEMS AND SOYBEAN PRODUCTIVITY IN SOUTHWEST REGION OF GOIÁS
}

\begin{abstract}
The tilling of areas in no-tillage to several years and the use of gypsum practices are observed among the farmers in southwestern Goiás. This study was carried out to evaluate the effect of gypsum rates $\left(0,1,2,4\right.$ e $\left.6 \mathrm{Mg} \mathrm{ha}^{-1}\right)$ on some chemical attributes in the soil's depth and in soybean yield in area under long-term no-till, with and without tillage. A complete randomized block scheme with a split-split-plot design with four replicates was used. The area has been conducted under no-till for several years in a dystrophic Clay Red-Yellow Latosol, in southwestern Goias, where calcium, magnesium, potassium and sulphate contents and effective cation exchange capacity were determined in the 0-5, 5-10, 10-20 and 20-40 cm layers. A higher concentration of cations and sulphate was observed in the $0-5 \mathrm{~cm}$ layer under no-tillage without revolving while the no-tillage with revolving, the sulphate concentrated in the 20 $40 \mathrm{~cm}$ layer. Although soybean yields were higher under no-till without revolving they were not affected by gypsum rates.
\end{abstract}

Index terms: cations, Cerrado, sulphate.

\section{INTRODUÇÃO}

O manejo de áreas em plantio direto por vários anos promove acúmulo de matéria orgânica no solo, principalmente em superfície, refletindo em melhoria na agregação do solo, aumento da atividade biológica, maior disponibilidade de nutrientes para as culturas, complexação de elementos tóxicos, além de promover aumento da CTC (Bayer \& Mielniczuk, 2008). No entanto, devido ao longo período de tempo sem revolvimento, essas áreas podem apresentar impedimentos físicos e químicos para o aprofundamento do sistema radicular das culturas. Dessa forma, o revolvimento do solo e a aplicação de gesso agrícola são alternativas para melhoria em profundidade do solo e, consequentemente, do ambiente para o crescimento das raízes de plantas.

O revolvimento do solo é uma opção para melhoria do ambiente radicular, embora encontre algumas limitações, como a necessidade de agilidade na semeadura, sobretudo em regiões em que se realiza a segunda safra, o alto custo energético e a falta de equipamentos apropriados para realização dessa operação na camada inferior a $20 \mathrm{~cm}$ de profundidade.

Apesar de alterar pouco o $\mathrm{pH}$ do solo, o gesso agrícola pode diminuir a toxidez do $\mathrm{Al}$ trocável para as plantas, reduzindo a atividade desse elemento na solução do solo (Alva et al., 1986), além de fornecer Ca e S para as plantas em profundidade. Ainda, o íon sulfato do gesso promove o carreamento de outras bases, como Mg e K das camadas superficiais do solo, para maiores profundidades (Silva et al., 1997; Caires et al., 2003), já que esse ânion desloca-se com facilidade para as camadas mais profundas do solo (Dias et al., 1994), podendo expor as plantas a eventuais deficiências, caso não se utilize o gesso com base em critérios técnicos.
Com isso, espera-se que o plantio direto com revolvimento apresente distribuição mais homogênea dos nutrientes nas camadas avaliadas do solo e que na área com plantio direto sem revolvimento esses nutrientes fiquem mais concentrados na superfície $(0-$ $5 \mathrm{~cm}$ ). Além disso, naquele manejo haverá melhor aeração e maior mineralização de nutrientes no solo, refletindo positivamente em termos de rendimento de grãos de soja, já que as raízes das plantas poderão aprofundar-se mais no solo. Ainda, o aumento das doses de gesso agrícola promoverá maior rendimento de grãos nessa cultura.

Nesse sentido, o presente trabalho teve por objetivo avaliar o efeito da aplicação de doses de gesso agrícola em alguns atributos químicos do solo e no rendimento de grãos de soja, em uma área sob plantio direto sem revolvimento e com revolvimento, na região sudoeste de Goiás.

\section{MATERIAL E MÉTODOS}

O experimento foi conduzido na Fazenda Primavera, situada no município de Serranópolis (GO), localizado nas coordenadas de $18^{\circ} 13^{\prime} 49$ " S e $51^{\circ} 58^{\prime} 41$ ” W, com altitude de $840 \mathrm{~m}$. O clima da região, conforme classificação de Köppen, é do tipo AWa, caracterizado como tropical úmido e seco, com estação chuvosa no verão e seca no inverno. A precipitação pluvial média anual é de $1.600 \mathrm{~mm}$, e a temperatura média anual, de $22^{\circ} \mathrm{C}$.

$\mathrm{O}$ solo da área experimental foi classificado como Latossolo Vermelho-Amarelo distrófico textura argilosa (Embrapa, 2006). A vegetação original da área experimental era do tipo Cerrado, a qual foi desmatada em 1984 e cultivada no sistema 
convencional (gradagens aradora e niveladora) até 1989 com plantio unicamente de soja, sendo, posteriormente, cultivada em plantio direto com a mesma cultura. A partir de 1992, até a presente data, a área vem sendo cultivada em sucessão soja/milho safrinha.

Desde o plantio até a colheita da cultura da soja (safra 2007/2008), a pluviosidade acumulada foi de $1.400 \mathrm{~mm}$; a precipitação pluvial foi bem distribuída nesse período e atendeu às necessidades hídricas para a produção máxima da cultura da soja, que varia entre 450 e 700 mm/safra (Doorembos \& Kassam, 1994).

Previamente à instalação do experimento, fez-se uma coleta de amostras de solo para determinação dos atributos químicos e granulométricos (Quadro 1) (Embrapa, 1999), das camadas de 0-5, 5-10, 10-20 e 20-40 cm.

No presente trabalho, os tratamentos foram dispostos em blocos completos balanceados ao acaso, em esquema de parcelas subsubdivididas, com quatro repetições. Nas parcelas, com área de 413,78 m² (6,13 x 67,5 m), foram utilizados dois manejos: plantio direto sem revolvimento (PDS) e plantio direto com revolvimento (PDR); nas subparcelas, com área de $82,76 \mathrm{~m}^{2}(6,13 \times 13,5 \mathrm{~m})$, foram aplicadas as cinco doses de gesso agrícola: 0, 1, 2, 4 e $6 \mathrm{Mg} \mathrm{ha}^{-1}$; e as subsubparcelas foram constituídas pelas quatro camadas de amostragem: 0-5, 5-10, 10-20 e 20$40 \mathrm{~cm}$.

Na instalação do experimento, aplicou-se calcário dolomítico com 94 \% de PRNT, 33,65 g kg-1 de CaO e $16,6 \mathrm{~g} \mathrm{~kg}^{-1}$ de $\mathrm{MgO}$ e 99,1 \% de reatividade. A aplicação foi realizada a lanço na superfície do solo, na dose de $1,6 \mathrm{Mg} \mathrm{ha-1}$, a qual foi calculada pelo método de saturação por bases, para elevá-la a $60 \%$, na camada de $0-20 \mathrm{~cm}$. O gesso agrícola foi proveniente de uma indústria de produção de ácido fosfórico de CatalãoGO. A aplicação do calcário ocorreu 22 dias antes da semeadura da soja, juntamente com a distribuição manual de gesso agrícola em superfície, em aplicação única.

Nas parcelas sob PDR, tanto o calcário quanto o gesso foram incorporados a $20 \mathrm{~cm}$ de profundidade, por meio de duas gradagens com uso de grade aradora, seguida de nivelamento da área por meio de grade niveladora. Nas parcelas sob PDS utilizou-se a mesma dose de calcário recomendada para a camada de 0 $20 \mathrm{~cm}$ de profundidade, não sendo incorporada, como apregoa tal sistema de manejo.

A cultura utilizada foi a da soja (Glycine max (L.) Merrill, cv 98Y11, Pioneer) no ano agrícola de 2007/ 2008. A adubação de plantio foi de $400 \mathrm{~kg} \mathrm{ha}^{-1} \mathrm{da}$ fórmula NPK, 02-20-18, sendo realizada na linha de semeadura. A soja foi semeada em 21 de outubro de 2007, com espaçamento de $45 \mathrm{~cm}$ entrelinhas e densidade de 400.000 sementes ha ${ }^{-1}$, para se atingir o estande de 16 plantas $\mathrm{m}^{-1}$. Os demais tratos culturais foram realizados conforme recomendações técnicas para a cultura nessa região; contudo, não foi realizada a inoculação das sementes e também não foi feita adubação de cobertura na área.

Após a maturação, a soja foi colhida; a área útil de cada subparcela correspondeu a $24 \mathrm{~m}^{2}$ e houve uniformidade no número de plantas colhidas entre os tratamentos. Após a colheita, as plantas foram trilhadas, sendo então determinado o rendimento de grãos.

Amostras de solo foram coletadas após a colheita da soja, ao acaso, nas linhas e entre as linhas de plantio. A coleta de solo foi realizada por meio de páde-corte, após ter sido cavada uma trincheira de $45 \mathrm{~cm}$ de comprimento no sentido perpendicular à linha de plantio, iniciando-se no meio de uma entrelinha e indo até o meio da outra entrelinha; em cada parcela foram coletadas 15 subamostras de solo, para compor uma amostra.

Após a coleta, as amostras foram encaminhadas ao Laboratório de Análise de Solos da Universidade Federal de Goiás, campus de Jataí, onde foram preparadas para comporem amostras de terra fina seca ao ar, para posterior análise dos componentes químicos do solo. Assim foram determinados os teores de $\mathrm{Ca}^{2+} \mathrm{e} \mathrm{Mg}^{2+}(\mathrm{KCl} 1 \mathrm{~mol} \mathrm{~L}-1), \mathrm{K}^{+}$(Mehlich-1), Ssulfato (método turbidimétrico, Vitti \& Suzuki, 1978)

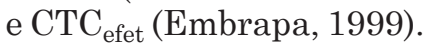

As análises estatísticas foram efetuadas para os teores de nutrientes no solo e rendimento de grãos de soja. Após análise de variância, as interações foram desdobradas, quando necessário, e os tratamentos

Quadro 1. Caracterização química e granulométrica de um Latossolo Vermelho-Amarelo distrófico, em quatro diferentes camadas

\begin{tabular}{|c|c|c|c|c|c|c|c|c|c|c|c|c|c|c|c|}
\hline Camada & $\mathbf{p H}_{\mathrm{H}_{2} \mathrm{O}}$ & $\mathbf{P}$ & $\mathbf{S}$ & $\mathrm{Ca}^{2+}$ & $\mathrm{Mg}^{2+}$ & $\mathbf{K}$ & $\mathrm{Al}^{3+}$ & $\mathbf{H}+\mathbf{A l}$ & CTC & SB & $\mathbf{m}$ & MO & Argila & Silte & Areia \\
\hline $\mathrm{cm}$ & & \multicolumn{2}{|c|}{$-\mathrm{g} \mathrm{dm}^{-3}-$} & \multicolumn{7}{|c|}{$-\mathrm{cmol}_{\mathrm{c}} \mathrm{dm}^{-3}$} & $\%$ & & g & & \\
\hline $0-5$ & 5,4 & 7,7 & 9,3 & 3,5 & 1,6 & 0,56 & 0,08 & 4,8 & 10,4 & 5,6 & 0,8 & 53,9 & 360 & 130 & 510 \\
\hline $5-10$ & 5,3 & 18,2 & 12,8 & 2,3 & 1,4 & 0,34 & 0,08 & 5,6 & 9,6 & 4,0 & 0,8 & 37,6 & 410 & 100 & 490 \\
\hline $10-20$ & 5,3 & 2,6 & 15,3 & 1,6 & 1,0 & 0,16 & 0,10 & 4,3 & 7,0 & 2,7 & 1,4 & 28,9 & 460 & 80 & 460 \\
\hline $20-40$ & 5,3 & 0,7 & 50,3 & 0,9 & 0,3 & 0,10 & 0,07 & 3,5 & 4,7 & 1,2 & 1,5 & 22,8 & 540 & 100 & 360 \\
\hline
\end{tabular}


qualitativos comparados pelo teste de Tukey a $5 \%$, calculando-se a DMS por meio do quadrado médio combinado, e os tratamentos quantitativos, por regressão. Todas as análises foram efetuadas utilizando-se o aplicativo computacional SAEG (Sistema para Análise Estatística).

\section{RESULTADOS E DISCUSSÃO}

Observa-se que o PDS proporcionou destacado aumento nos teores de $\mathrm{Ca}^{2+}$ na camada de $0-5 \mathrm{~cm}$, o qual foi superior em relação ao PDR (Figura 1) em todas as doses de gesso aplicadas. Os teores desse elemento variaram de 5,79 (sem aplicação de gesso) a $11,75 \mathrm{cmol}_{\mathrm{c}} \mathrm{dm}^{-3}$ (com $6 \mathrm{Mg} \mathrm{ha}^{-1}$ de gesso), representando $68 \%$ da $\mathrm{CTC}_{\text {efet }}$ do solo na maior dose de gesso aplicada, na camada de $0-5 \mathrm{~cm}$. Esse aumento acima de $65 \%$ na participação do $\mathrm{Ca}^{2+}$ na $\mathrm{CTC}_{\text {efet }}$ (Vitti et al., 2006) pode ser um indicativo de desequilíbrio de cátions no solo.

Nota-se que somente sem a aplicação de gesso agrícola os teores de $\mathrm{Ca}^{2+}$ foram semelhantes nas camadas de $0-5$ e $5-10 \mathrm{~cm}$ no PDR (Figura 1 ). Nas demais camadas, para os dois manejos, houve diminuição nos teores de $\mathrm{Ca}^{2+}$ até a profundidade de $40 \mathrm{~cm}$, sendo, nesta camada, esses teores semelhantes nos dois manejos. Na camada de $5-10 \mathrm{~cm}$, observamse teores de $\mathrm{Ca}^{2+}$ levemente superiores no PDR devido ao efeito de homogeneização ocorrido com o revolvimento; houve diferença significativa entre os dois manejos, nesta camada, nas doses de gesso de $2 \mathrm{e}$ $6 \mathrm{Mg} \mathrm{ha}^{-1}$ (Figura 1c,e). Nas camadas de 10-20 e 20$40 \mathrm{~cm}$, quando se comparam os dois manejos, os teores de $\mathrm{Ca}^{2+}$ mostraram valores semelhantes nas doses de gesso de 1 e $4 \mathrm{Mg} \mathrm{ha}^{-1}$ (Figura 1b,d).

$\mathrm{O}$ revolvimento não proporcionou aumento nos teores $\mathrm{Ca}^{2+}$ em profundidade, considerando somente uma avaliação após quatro meses da aplicação do gesso agrícola. Contudo, deve-se considerar que esses resultados podem ser influenciados pelas condições inerentes à área experimental, às condições climáticas do ano agrícola, à fertilidade do solo e ao manejo que vem sendo adotado ao longo dos anos.

Com relação ao $\mathrm{Mg}^{2+}$, quando se comparam os dois manejos, nota-se que no PDR houve homogeneização nos teores de $\mathrm{Mg}^{2+}$ até $10 \mathrm{~cm}$ de profundidade (Figura 2) pelo processo de revolvimento do solo. No PDS, ocorre a formação de um gradiente de concentração a partir da superfície até a camada de 10-20 cm (Figura 2); exceto no tratamento sem aplicação de gesso, não houve diferença entre as camadas de 10-20 e 20$40 \mathrm{~cm}$ em relação aos teores de $\mathrm{Mg}^{2+}$. No PDR, nestas mesmas camadas e para os tratamentos sem gesso e $1 \mathrm{Mg}$ ha $^{-1}$, houve diminuição nos teores desse nutriente em profundidade (Figura 2a,b).

Os teores de $\mathrm{Mg}^{2+}$ são superiores na camada superficial $(p<0,05)$, no tratamento PDS, somente
CÁLCIO, $\mathrm{cmol}_{\mathrm{c}} \mathrm{dm}^{-3}$
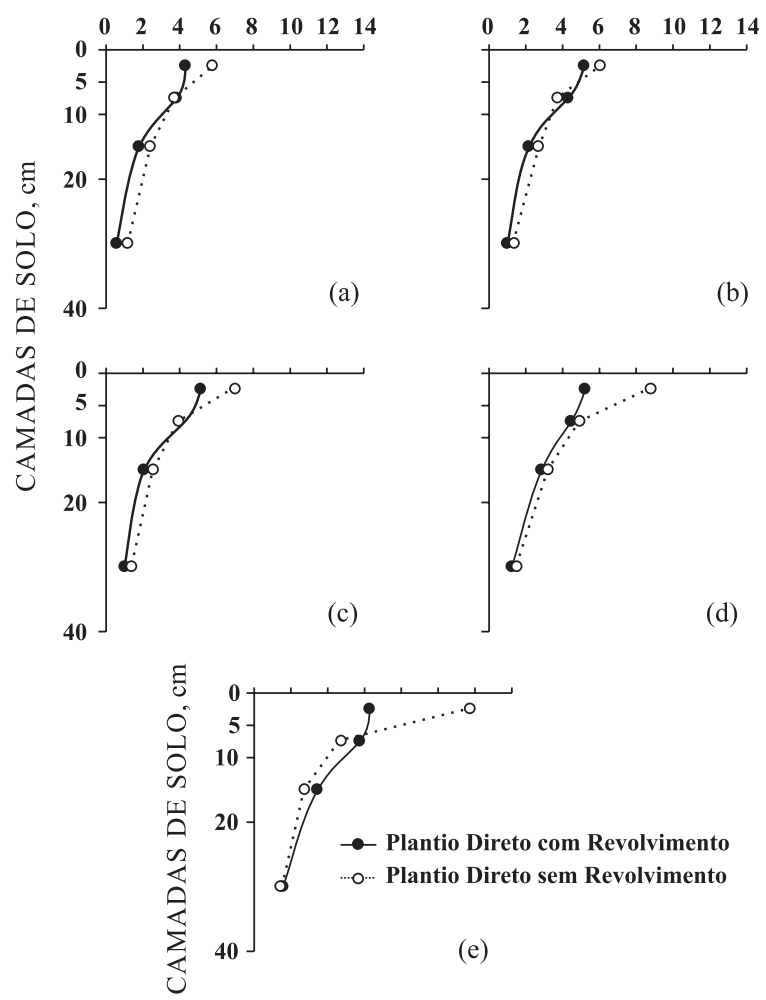

DMS manejo $x$ profundidade $=0,5144$

DMS profundidade $x$ manejo $=\mathbf{0 , 5 1 9 5}$

Figura 1. Teores de cálcio trocável em um Latossolo Vermelho-Amarelo distrófico sob dois tipos de manejo do solo (Tukey a $5 \%$ ): sem gesso (a), $1 \mathrm{Mg} \mathrm{ha}^{-1}$ (b), $2 \mathrm{Mg} \mathrm{ha}^{-1}$ (c), $4 \mathrm{Mg} \mathrm{ha}^{-1}$ (d) e $6 \mathrm{Mg} \mathrm{ha}^{-1}(\mathrm{e})$.

nas doses de gesso de 1 e $2 \mathrm{Mg} \mathrm{ha}^{-1}$ (Figura 2b,c). Na camada de 5-10 cm, o PDR apresentou teores de $\mathrm{Mg}^{2+}$ mais elevados em todas as doses de gesso aplicadas, mostrando que, com o revolvimento, ocorre distribuição mais homogênea entre as duas camadas superficiais, enquanto no PDS a maior concentração desse nutriente ocorre em superfície. Nas camadas de 1020 e $20-40 \mathrm{~cm}$, os teores desse nutriente foram semelhantes nos dois manejos adotados (Figura 2), considerando um período de quatro meses entre a aplicação do gesso e a amostragem do solo para determinação dos seus teores.

Com relação ao $\mathrm{K}^{+}$, observa-se maior teor desse nutriente na camada de $0-5 \mathrm{~cm}$, no tratamento sem gesso agrícola, em PDS (Figura 3a), quando comparado ao PDR. Isso deve-se ao não revolvimento do solo, possibilitando a concentração deste na superfície em vez de ser incorporado a uma camada maior de solo, e também aos teores desse nutriente inicialmente encontrados no solo por meio da realização anual de adubação potássica na linha por ocasião da semeadura, além da ciclagem desse nutriente via resíduos vegetais. O K está presente em altos teores nos tecidos das plantas, as quais, ao 

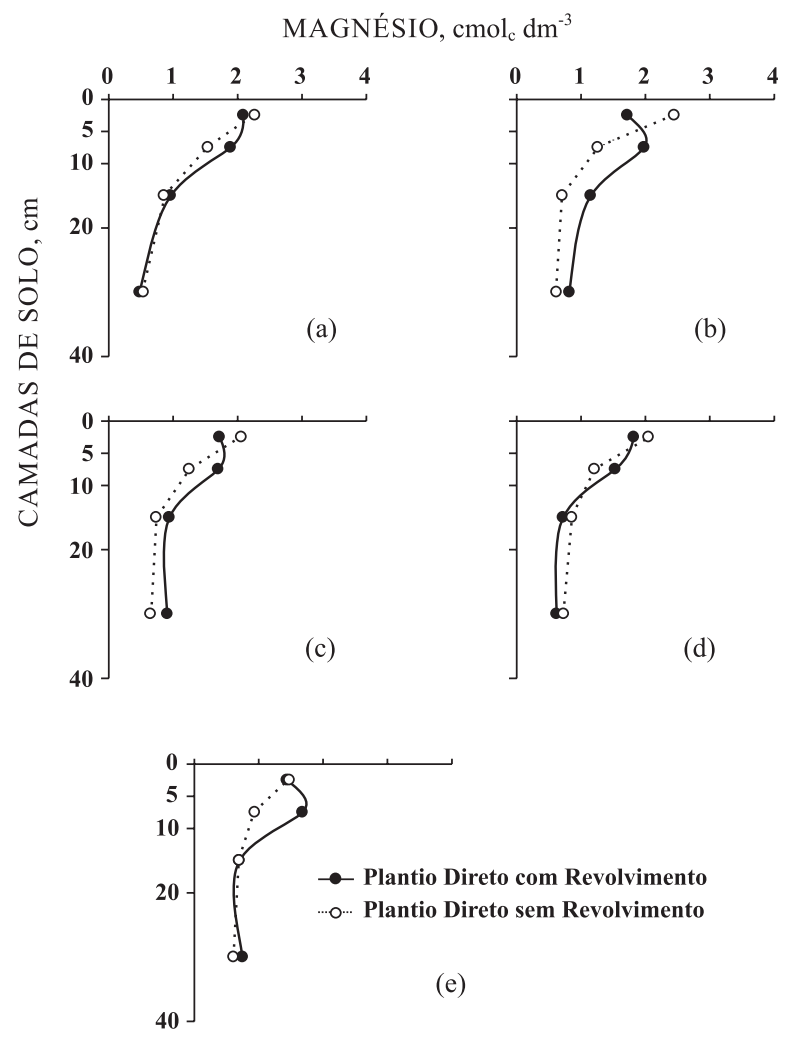

DMS manejo $x$ profundidade $=\mathbf{0 , 2 9 4 7}$

DMS profundidade $\mathrm{x}$ manejo $=\mathbf{0 , 2 7 3 8}$

Figura 2. Teores de magnésio trocável em um Latossolo Vermelho-Amarelo distrófico sob dois tipos de manejo do solo (Tukey a $5 \%$ ): sem gesso (a), $1 \mathrm{Mg} \mathrm{ha}^{-1}$ (b), $2 \mathrm{Mg} \mathrm{ha}^{-1}$ (c), $4 \mathrm{Mg} \mathrm{ha}^{-1}$ (d) e $6 \mathrm{Mg} \mathrm{ha}^{-1}(\mathrm{e})$.

serem depositadas no solo, liberam-no rapidamente, pois este permanece livre no seu interior (Ernani et al., 2007). Outros autores também encontraram maiores teores de $\mathrm{K}^{+}$na superfície do solo em PD (Klepker \& Anghinoni, 1995).

Os teores de $\mathrm{K}^{+}$foram semelhantes entre os dois manejos na camada de 10-20 cm (Figura 3), indicando que, no experimento em questão, a incorporação não alterou de maneira substancial o teor de $\mathrm{K}^{+}$nessa camada. Na camada de $20-40 \mathrm{~cm}$, os teores de $\mathrm{K}^{+}$ também não diferiram quando se compararam os dois manejos adotados. Na dose de $6 \mathrm{Mg}^{\text {ha-1 }}{ }^{-1}$ de gesso, o PDR apresentou teor mais elevado de $\mathrm{K}^{+}$, quando comparado ao PDS, na camada de 0-5 cm (Figura 3e), pois nessa dose houve descida desse nutriente, juntamente com o sulfato, para camadas mais profundas do solo devido ao excesso de $\mathrm{Ca}^{2+}$, deslocando o $\mathrm{K}^{+}$adsorvido pelos coloides para a solução do solo (Meurer et al., 2006).

No tratamento PDS, os valores da $\mathrm{CTC}_{\text {efet }}$ partiram de 11 para $17 \mathrm{cmol}_{\mathrm{c}} \mathrm{dm}^{-3}$ (Figura $4 \mathrm{a}, \mathrm{e}$ ) com o aumento nas doses de gesso de 0 para $6 \mathrm{Mg} \mathrm{ha}^{-1}$ na camada de 0-5 cm, acompanhando o aumento ocorrido nos teores de $\mathrm{Ca}^{2+}$ (Figura 1). Tanto no PDS como no PDR, os teores de $\mathrm{Ca}^{2+}$ influenciaram os valores da $\mathrm{CTC}_{\text {efet }}$ (Figura 4) em todas as camadas avaliadas. Com isso, demonstra-se que o aumento da $\mathrm{CTC}_{\text {efet }}$ do solo, quando se aplica gesso, é principalmente devido ao aumento nos teores de $\mathrm{Ca}^{2+}$, já que nas camadas de $0-5$ e 5$10 \mathrm{~cm}$ os teores de $\mathrm{Mg}^{2+}$ (Figura 2) e $\mathrm{K}^{+}$(Figura 3) reduziram com a aplicação de doses crescentes de gesso.

No PDS, os valores da $\mathrm{CTC}_{\text {efet }}$ foram superiores, na camada superficial do solo, nas doses de gesso de 2,4 e $6 \mathrm{Mg} \mathrm{ha}^{-1}$ (Figura 4c,d,e), devido à maior concentração de $\mathrm{Ca}^{2+}$ nessa camada, quando comparado ao PDR. Neste, houve diferença na camada de 20-40 cm para as doses de gesso de 2 e $4 \mathrm{Mg} \mathrm{ha}^{-1}$. Falleiro et al. (2003) encontraram maiores

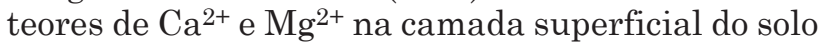
em PD, quando comparado a sistemas com preparo do solo, em um Argissolo, o que refletiu em maior valor de $\mathrm{CTC}_{\text {ef }}$.

Portanto, a aplicação de gesso agrícola pode aumentar a saturação por $\mathrm{Ca}^{2+}$ na $\mathrm{CTC}_{\text {ef }}$, além do que o sulfato pode se ligar ao $\mathrm{Al}^{3+}$ e reduzir seu teor e, ou, atividade no solo e causar aumento na CTC

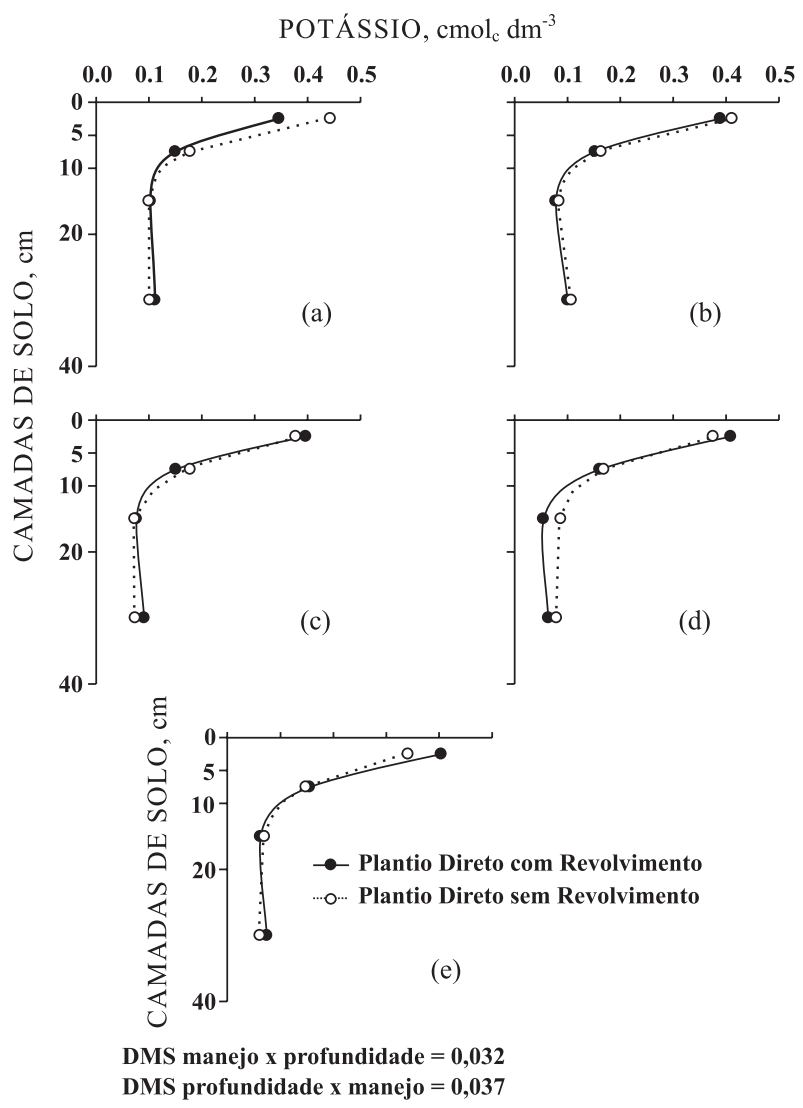

Figura 3. Teores de potássio em um Latossolo Vermelho-Amarelo distrófico sob dois tipos de manejo do solo (Tukey a $5 \%$ ): sem gesso (a), $1 \mathrm{Mg} \mathrm{ha}^{-1}$ (b), $2 \mathrm{Mg} \mathrm{ha}^{-1}$ (c), $4 \mathrm{Mg} \mathrm{ha}^{-1}$ (d) e $6 \mathrm{Mg} \mathrm{ha}^{-1}(\mathrm{e})$. 


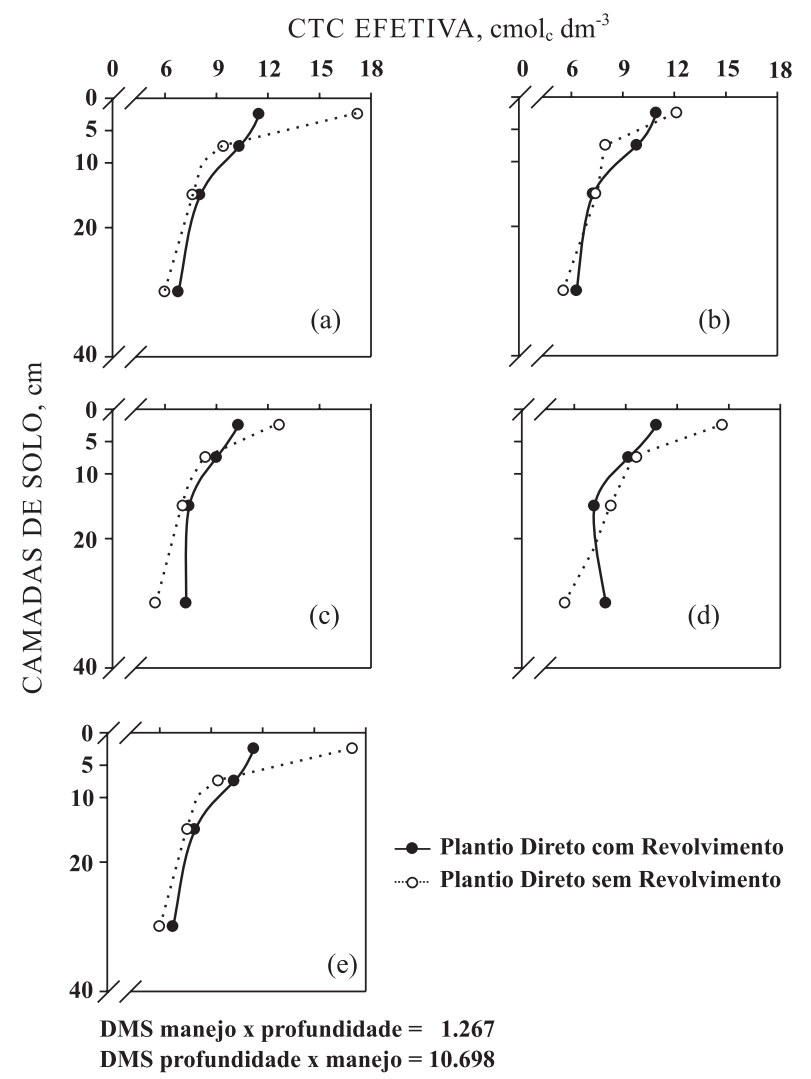

Figura 4. Capacidade de troca de cátions efetiva em um Latossolo Vermelho-Amarelo distrófico sob dois tipos de manejo do solo (Tukey a $5 \%$ ): sem gesso (a), $1 \mathrm{Mg} \mathrm{ha}^{-1}$ (b), $2 \mathrm{Mg} \mathrm{ha}^{-1}$ (c), $4 \mathrm{Mg} \mathrm{ha}^{-1}$ (d) e $6 \mathrm{Mg} \mathrm{ha}^{-1}(\mathrm{e})$.

potencial do solo (Sousa et al., 2007). Ainda, no PDS o aumento da $\mathrm{CTC}_{\text {efet }}$ na superfície também pode ser devido à adsorção específica de sulfato, por aumentar a carga líquida negativa do solo (Meurer et al., 2006).

Nota-se que no PDS, nas doses de gesso de $4 \mathrm{e}$ $6 \mathrm{Mg} \mathrm{ha}^{-1}$, ocorreu acentuado aumento nos teores de $\mathrm{S}_{-} \mathrm{SO}_{4}{ }^{2-}$ na camada de $0-5 \mathrm{~cm}$, quando comparado ao PDR (Figura 5). Além disso, verificou-se que há maior concentração de $\mathrm{S}_{-} \mathrm{SO}_{4}{ }^{2-}$ na camada de $20-40 \mathrm{~cm}$, resultado também obtido por Silva et al. (1997), demonstrando que esse íon desce com facilidade em profundidade no solo, carreando consigo $\mathrm{K}^{+}, \mathrm{Mg}^{2+} \mathrm{e}$, principalmente, $\mathrm{Ca}^{2+}$ (Sousa et al., 2007).

O tratamento PDR apresentou maiores teores de S- $\mathrm{SO}_{4}{ }^{2-}$ em relação ao PDS na camada de $20-40 \mathrm{~cm}$, exceto para a dose de $6 \mathrm{Mg}^{\text {ha-1 }}{ }^{-1}$ de gesso (Figura 5), demonstrando que o revolvimento possibilita a descida mais rápida do $\mathrm{S}_{-} \mathrm{SO}_{4}{ }^{2-}$ em profundidade; a movimentação de $\mathrm{S}_{-} \mathrm{SO}_{4}{ }^{2-}$ no solo foi maior com as maiores doses de gesso aplicadas, tanto no PDS quanto no PDR, concordando com os resultados de Caires et al. (2003).
A distribuição do $\mathrm{S}_{-} \mathrm{SO}_{4}{ }^{2-}$ foi uniforme em profundidade, no PDS, no tratamento sem gesso agrícola (Figura 5a). Nas doses de gesso de 4 e

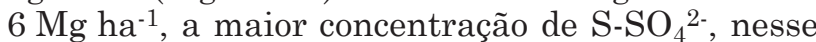
manejo, ocorreu na superfície, quando comparada às demais camadas (Figura 5d, e). No entanto, no PDR, os teores de $\mathrm{S}_{-} \mathrm{SO}_{4}{ }^{2-}$ apresentaram-se superiores na camada de 20-40 cm, exceto para a dose de $6 \mathrm{Mg} \mathrm{ha}^{-1}$ (Figura 5).

O teor do íon $\mathrm{S}_{-} \mathrm{SO}_{4}{ }^{2-}$ é influenciado pela precipitação pluvial, temperatura, adubação, manejo dos restos culturais e fertilizantes utilizados (Nogueira $\&$ Melo, 2003). A distribuição das chuvas no período da cultura da soja foi normal, podendo ser um dos responsáveis pelas variações nos teores de $\mathrm{S}_{-} \mathrm{SO}_{4}{ }^{2-}$ no solo, por favorecer a migração desse íon em profundidade, já que a permanência desse ânion ocorre quase que totalmente na solução do solo (Dias et al., 1994). Pelo fato de o $\mathrm{S}_{-} \mathrm{SO}_{4}{ }^{2-}$ deslocar-se rapidamente em profundidade, esse nutriente merece atenção para que não se torne limitante às culturas, sobretudo em solos com baixos teores de matéria orgânica, sua principal reserva.

Em relação ao rendimento de grãos de soja, o PDS mostrou-se superior quando comparado ao PDR

SULFATO, $\mathrm{mg} \mathrm{dm}^{-3}$

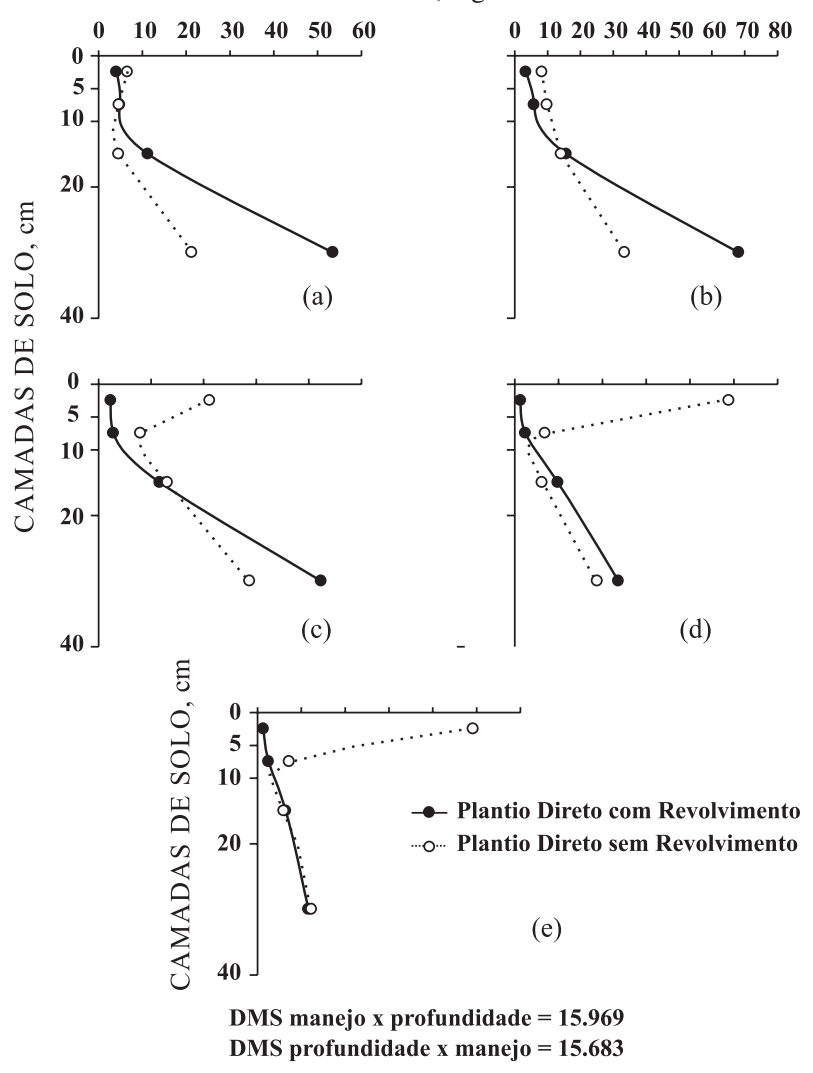

Figura 5. Teores de sulfato em um Latossolo Vermelho-Amarelo distrófico sob dois tipos de manejo do solo (Tukey a $5 \%$ ): sem gesso (a), $1 \mathrm{Mg} \mathrm{ha}^{-1}$ (b), $2 \mathrm{Mg} \mathrm{ha}^{-1}$ (c), $4 \mathrm{Mg} \mathrm{ha}^{-1}$ (d) e $6 \mathrm{Mg} \mathrm{ha}^{-1}(\mathrm{e})$. 
(Figura 6). Nota-se que a não aplicação de gesso agrícola promoveu a maior diferença entre os manejos; o PDS sobressai com $440 \mathrm{~kg} \mathrm{ha}^{-1} \mathrm{em}$ relação ao PDR, o que equivale a 7,3 sacas de $60 \mathrm{~kg}$ de grãos de soja. A menor diferença ocorreu na dose de $6 \mathrm{Mg} \mathrm{ha}^{-1}$, sendo de $215 \mathrm{~kg} \mathrm{ha}^{-1}$, o que equivale a 3,58 sacas de $60 \mathrm{~kg}$, apresentando-se superior no PDS.

Não foi encontrada resposta em rendimento de grãos de soja com as doses de gesso aplicadas, em nenhum dos dois manejos (Figura 6), já que os teores de $\mathrm{Ca}^{2+}$ encontravam-se acima do valor mínimo para se recomendar a aplicação de gesso agrícola, o qual, de acordo com Sousa \& Lobato (2004), é de $0,5 \mathrm{cmol}_{\mathrm{c}} \mathrm{dm}^{-3}$, nas camadas de $20-40$ e $40-60 \mathrm{~cm}$, e a saturação de $\mathrm{Al}^{3+}$, abaixo de $20 \%$. Os teores de $\mathrm{S}$ $\mathrm{SO}_{4}{ }^{2-}$ também se encontraram acima dos teores mínimos, nas quatro camadas amostradas, e a precipitação pluvial foi bem distribuída, atendendo à necessidade da cultura. Ausência de resposta às doses de gesso foi encontrada em outros trabalhos realizados tanto em PD como em áreas em plantio convencional (Quaggio et al., 1993; Caires et al., 2003).

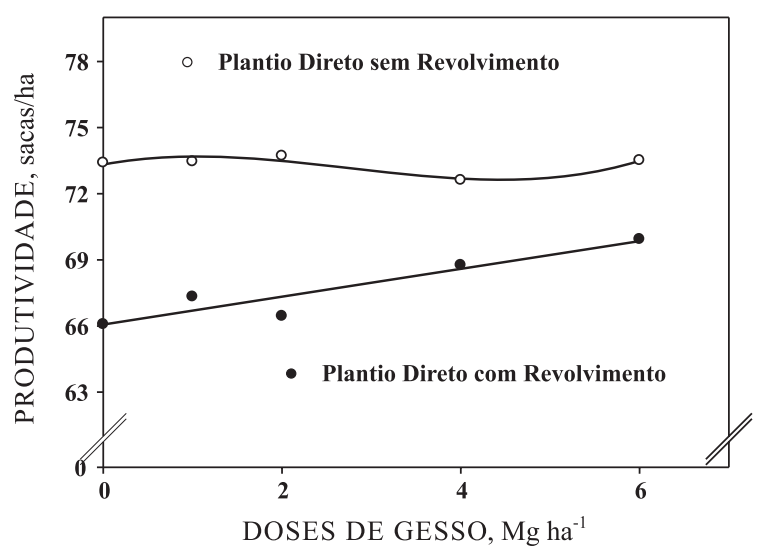

Figura 6. Rendimento de grãos de soja em função de doses de gesso em área de plantio direto sem revolvimento e plantio direto com revolvimento.

A incorporação favorece o contato da fonte de C com os microrganismos, além de o revolvimento favorecer a aeração e expor a matéria orgânica que está dentro dos agregados, facilitando o consumo do C pela microbiota decompositora, com consequente liberação de $\mathrm{CO}_{2}$ e dos nutrientes. No $\mathrm{PD}$ surgem as propriedades emergentes do sistema, que são as interações entre os componentes do sistema (solo, minerais, plantas e microrganismos), resultando em estruturas cada vez mais complexas e diversificadas, capacitando o sistema a funcionar em múltiplas situações e, dessa forma, manter a sua integridade diante de perturbações (Vezzani, 2001), justificando assim o maior rendimento de grãos no PDS, neste experimento.

\section{CONCLUSÕES}

1. No plantio direto sem revolvimento ocorre maior concentração de $\mathrm{Mg}$ e Ca trocável na camada superficial, refletindo em maiores valores de capacidade de troca de cátions efetiva.

2. O teor de K trocável foi superior no plantio direto sem revolvimento (PDS) e sem aplicação de gesso agrícola, enquanto no plantio direto com revolvimento foi superior para a dose de $6 \mathrm{Mg} \mathrm{ha}^{-1}$, ambos na camada de $0-5 \mathrm{~cm}$.

3. Os maiores teores de sulfato no solo, no plantio direto sem revolvimento, encontram-se na camada superficial; já no plantio direto com revolvimento, o maior teor ocorreu na camada de $20-40 \mathrm{~cm}$.

4. O plantio direto sem revolvimento apresentou maior rendimento de grãos de soja em relação ao plantio direto com revolvimento, independentemente da dose de gesso aplicada.

5. Não houve resposta, em termos de rendimento de grãos de soja, às doses de gesso aplicadas tanto em plantio direto sem revolvimento quanto em plantio direto com revolvimento.

\section{LITERATURA CITADA}

ALVA, A.K.; BLAMEY, F.P.C.; EDWARDS, D.G. \& ASHER, C.J. An evolution of aluminum indices to predict aluminum toxicity to plants grown in nutrient solutions. Comm. Soil Sci. Plant Anal., 17:1271-1280, 1986.

BAYER, C. \& MIELNICZUK, J. Dinâmica da matéria orgânica. In: SANTOS, G.A.; SILVA, L.S.; CANELLAS, L.P. \& CAMARGO, F.A.O., eds. Fundamentos da matéria orgânica do solo: Ecossistemas tropicais e subtropicais. Porto Alegre, Metrópole, 2008. p.7-18.

CAIRES, E.F.; BLUM, J.; BARTH, G.; GARBUIO, F.J. \& KUSMAN, M.T. Alterações químicas do solo e resposta da soja ao calcário e gesso aplicados na implantação do sistema plantio direto. R. Bras. Ci. Solo, 27:275-286, 2003.

DIAS, L.E.; ALVAREZ V., V.H.; COSTA, L.M. \& NOVAIS, R.F. Dinâmica de algumas formas de $\mathrm{S}$ em colunas de solos tratados com diferentes doses de fósforo e gesso. R. Bras. Ci. Solo, 18:373-380, 1994.

DOOREMBOS, J. \& KASSAM, A.H. Efeito da água no rendimento das culturas. Campina Grande, Universidade Federal da Paraíba, 1994. 306p.

EMPRESA BRASILEIRA DE PESQUISA AGROPECUÁRIA EMBRAPA. Centro Nacional de Pesquisa de Solos. Sistema brasileiro de classificação de solos. Brasília, Embrapa Produção de Informação; Rio de Janeiro, Embrapa Solos, 2006. 306p.

EMPRESA BRASILEIRA DE PESQUISA AGROPECUÁRIA EMBRAPA. Manual de análises químicas de solos, plantas e fertilizantes. Brasília, Embrapa Comunicação para Transferência de Tecnologia, 1999. 370p. 
ERNANI, P.R.; ALMEIDA, J.A. \& SANTOS, F.C. Potássio. In: NOVAIS, R.F.; ALVAREZ V., V.H.; BARROS, N.F.; FONTES, R.L.F.; CANTARUTTI, R.B. \& NEVES, J.C.L., eds. Fertilidade do solo. Viçosa, MG, Sociedade Brasileira de Ciência do Solo, 2007. p.551-594.

FALLEIRO, R.M.; SOUZA, C.M.; SILVA, C.S.W.; SEDIYAMA, C.S.; SILVA, A.A. \& FAGUNGES, J.L. Influência dos sistemas de preparo nas propriedades químicas e físicas do solo. R. Bras. Ci. Solo, 27:1097-1104, 2003.

KLEPKER, D. \& ANGHINONI, I. Características físicas e químicas do solo afetadas por métodos de preparo e modos de adubação. R. Bras. Ci. Solo, 19:395-401, 1995.

MEURER, E.J.; RHEINHEIMER, D. \& BISSANI, C.A Fenômenos de sorção em solos. In: MEURER, E.J., ed. Fundamentos da química do solo. Porto Alegre, Evangraf, 2006. p.117-162.

NOGUEIRA, M.A. \& MELO, W.J. Enxofre disponível para a soja e atividade de arilsulfatase em solo tratado com gesso agrícola. R. Bras. Ci. Solo, 27:655-663, 2003.

QUAGGIO, J.A.; RAIJ, B.van; GALLO, P.B. \& MASCARENHAS, H.A.A. Respostas da soja à aplicação de calcário e gesso e lixiviação de íons no perfil do solo. Pesq. Agropec. Bras., 28:375-383, 1993.
SILVA, N.M.; RAIJ, B.van; CARVALHO, L.H.; BATAGLIA, O.C. \& KONDO, J.I. Efeitos do calcário e do gesso nas características químicas do solo e na cultura do algodão. Bragantia, 56:389-401, 1997.

SOUSA, D.M.G.; MIRANDA, L.N. \& OLIVEIRA, S.A. Acidez do solo e sua correção. In: NOVAIS, R.F.; ALVAREZ V., V.H.; BARROS, N.F.; FONTES, R.L.F.; CANTARUTTI, R.B. \& NEVES, J.C.L., eds.. Fertilidade do solo. Viçosa, MG, Sociedade Brasileira de Ciência do Solo, 2007. p.205274.

SOUSA, D.M.G. \& LOBATO, E. Correção da acidez do solo. In: SOUSA, D.M.G. \& LOBATO, E., eds. Cerrado: Correção do solo e adubação. Brasília, Embrapa Informação Tecnológica, 2004. p.81-96.

VEZZANI, F.M. Qualidade do sistema solo na produção agrícola. Porto Alegre, Universidade Federal do Rio Grande do Sul, 2001. 184p. (Tese de Doutorado)

VITTI, G.C.; LIMA, E. \& CICARONE, F. Cálcio, magnésio e enxofre. In: FERNANDES, M.S., ed. Nutrição mineral de plantas. Viçosa, MG, Sociedade Brasileira de Ciência do Solo, 2006. p.299-325. 